\section{Seabird Bycatch: Trends, Roadblocks, and Solutions}

Edited by Edward F. Melvin and Julia K. Parrish. 2001. University of Alaska Sea Grant AK-SG-01-01, Fairbanks, Alaska. viii + 206 pages. U.S.\$20.00.

The incidental catch of various water birds and other aquatic organisms (e.g., turtles, sea otters, porpoises, seals) in fishing nets has long been of concern to naturalists for conservation reasons and to the fishing industry for economic reasons. However, until recently this issue has been on the "back burner" compared with more pressing and widespread environmental problems. The advent of intensified fishing efforts, huge factory ships, and collapsing fish stocks have elevated this bycatch into both a major international environmental issue and a serious economic problem. This book, essentially the proceedings of a symposium, presents a recent update on the extent of the problem in marine waters, world-wide, evaluations of several proposed solutions as they apply to specific fisheries and problems that have yet to be overcome.

The editors begin the book with a short preface that outlines the history and extent of the problem, especially since it was identified as a major conservation issue in the early 1970s. The first full chapter is a synthesis, also by the editors, of a symposium organized by the Pacific Seabird Group in Blaine, Washington, in 1999. The synthesis summarizes the complexity of the problem, "roadblocks" in the way of solving it and guidelines to possible solutions. The remainder of the book consists of nine peer-reviewed, scientific papers (eight of which were presented at the symposium) and seven abstracts. Two of the papers were reprinted from recent (1999 and 2000) scientific journals. One paper, by John Cooper, John Croxall and Kim Rivera outlines the complexities of international efforts to re- duce bycatch through research, local and international regulations and cooperation among scientists, the fishing industry and conservation groups. An afterword by Craig Harrison graphically illustrates the complexity of the problem by outlining the political and practical difficulties of coordinating efforts to reduce bycatch in the sockeye salmon fishery in the "shared waters" of British Columbia and Washington, where two federal, one provincial and one state government share jurisdiction with "21 Native American tribes" [a total that applies only to Washington and omits the first nations of British Columbia].

The rest of the papers and abstracts document the extent of the bycatch in specific fisheries, results of various experiments to reduce bycatch, and attempts to measure the impact of specific fisheries on specific populations of birds. As some seabirds spend nonbreeding times thousands of kilometers from their breeding sites, measuring the effects of a specific fishery on a particular breeding population is very difficult, especially as many seabirds are long-lived and don't breed every year. Moreover, fishing in a given area may affect some species much more profoundly than their close relatives (for example, effects of bycatch on Black-footed Albatross populations are much more significant than on Laysan Albatrosses) and may affect different age groups differently (for example, juvenile Black-footed Albatrosses are caught at a higher rate than adults). Research presented in this volume from the Atlantic, Pacific and Southern (Antarctic) oceans shows that modifications to fishing gear (weights, design, visual and acoustic alerts), timing of fishing (daily and seasonally) and other techniques can reduce bycatch substantially without substantially reducing the take of target species, but that these modifications have different effects on the rate of bycatch of different species and sometimes of a given species

in different areas, different times of the day or different seasons. Banding continues to be helpful in sorting out

the origins of birds caught in specific fisheries, while higher tech tracking devices and research on genetic markers are also starting to improve our knowledge of the complexities of movements by these highly mobile species. Albatrosses receive the greatest amount of attention, but data on various other "tubenoses," alcids, larids and some marine mammals are also presented.

Canadian content figures prominently in this book. A 1972 paper by Canadian C. Eric Tull and co-authors on the magnitude of Thick-billed Murre mortality in Greenland fisheries is credited (page v) in drawing attention to the significance of fisheries in seabird population declines, and international legal efforts to reduce bycatch in longlines stem from a resolution at a 1996 meeting in Montreal of the World Conservation Congress of the World Conservation Union (page 11). Data from British Columbia are included in a genetics (DNA) study of the breeding locations of Common Murres entangled in fishing nets in Washington's San Juan Islands and Puget Sound (pages 125-127) and in an abstract (pages 191-192) on seabird avoidance experiments in northern Pacific waters. Other papers and abstracts on observations and research in Alaskan and Washington waters involve populations of birds that spend portions of their lives in British Columbian waters. Research from Atlantic coast provinces and British Columbia are cited frequently.

This book provides a useful compilation of recent developments on a complex issue, with plenty of information on legal (national and international)/political aspects, recent research on seabird movements, recent research on genetics of seabird populations, and practical tests of various techniques under a variety of conditions in a variety of waters. The literature cited 
sections provide numerous additional references for those requiring further information. The book should be on the library shelves of any researchers, government agencies and non-government conservation and scientific organizations studying seabird biology and/ or the conservation of seabirds. Errors appear to be few - the reference to Wilson et al. (1985) cited on page 116 is not listed in that chapter's literature cited section, which includes two references that don't appear to have been cited. However, since most of the chapters are written as scientific papers, some may be too technical for some readers. The review by Cooper et al. of legal and quasilegal aspects of the issue provides a valuable reference compendium, but is so riddled with acronyms that I found myself wishing for a glossary. I also hope that the seven abstracts at the end of the book are expanded into full papers somewhere. As valuable a contribution as the book is in itself, this volume will undoubtedly also stimulate more research

\section{The Life of Mammals}

By David Attenborough. 2002. Princeton University Press, New Jersey. 320 pages, U.S.\$29.95.

As the latest edition in the BBC "Life" series combining television and print media, the book on mammals is nicely illustrated with a good selection of colour photographs that closely follows the engaging text by David Attenborough as he presents interesting stories on these fascinating animals. The first chapter, "A Winning Design", starts off with the ability of mammals to adapt to different environments on earth, including the harsh arctic conditions where lemmings live year round. After describing some basic characters of mammals, such as hair and the production of milk, there is a general introduction to the origin and evolution of this group of warm-blooded organisms. The chapter finishes off with two early mammalian radiations that cover the egg-laying monotremes and the marsupials, which give birth to under-developed young.

The remaining nine chapters deal with the placental eutherian mammals but instead of continuing to describe them by scientific groups the format switches to artificial categories such as diet and habitat. This unnatural classification seems awkward at times with bats, which people can readily identify with, split into two separate chapters, "Insect Hunters" (curiously including vampire bats) and "Life in the Trees" (although some insect-eating bats also live in trees). There was a missed opportunity to educate readers in scientific classification and evolution while still entertaining them with a plethora of amazing natural history stories.

Primates get star billing in the book with the last two and a half chapters devoted to this charismatic order of mammals. Although the higher-level taxonomy (or common names employed) is not current, it begins with prosimians as an early branch of the primates. The latest view is that this is not a natural group be- that will require another update before long. Such an update could usefully also include papers or chapters on aquatic bird bycatch of fisheries on inland waters, such as those of the Great Lakes, several large prairie province lakes and similar lakes on other continents.

MARTin K. MCNiCHOLL

4735 Canada Way, Burnaby, British Columbia V5G 1L3 Canada

cause, for example, tarsiers are more closely related to monkeys and apes, as alluded to but nonetheless still included in the chapter with lemurs. The other primates are grouped to cover the new and old world monkeys, and ending with the gibbons and great apes, including a branch for humans. The last half chapter concentrates on both physical and social anthropology from the first evidence of bipedal locomotion to cultivation and civilization.

The book is definitely aimed at a general but knowledgeable audience with an interest in nature and mammals. I am sure, however, that practising biologists will still find a few facts new to them in their nonspecialist group because the background research is relatively good. It was nice to see some recent scientific hypotheses on mammalian evolution making it into the book such as the close relationship between whales and hippopotamuses. But some other emerging ideas based primarily on molecular data did not, including the association of bats with carnivores, ungulates and whales, as opposed to insectivores, or tree shrews, flying lemurs and primates.

My criticisms are mostly biologically oriented because the book is attractively presented with most photographs of good quality and information well written. But there should be more books that combine current scientific research with an explanation of the deeper implications or processes involved for wider distribution to the general public looking for meaningful substance beyond the usual cursory facts.

BurTON K. LIM

Centre for Biodiversity and Conservation Biology, Royal Ontario Museum, 100 Queen's Park, Toronto, Ontario M5S 2C6 Canada

Geographic Variation in Size and Shape of 